\title{
Terapia Ocupacional Social, pessoas trans e Teoria Queer: (re)pensando concepçóes normativas baseadas no gênero e na sexualidade
}

\author{
Késia Maria Maximiano de Melo \\ Universidade Estadual Paulista “Júlio de Mesquita Filho" - UNESP, Marília, SP, Brasil.
}

\begin{abstract}
Resumo: A partir de minhas aproximações teóricas e práticas com a temática das vivências trans, busquei, neste artigo, discutir essas vivências e os desdobramentos decorrentes das concepções normativas de gênero e sexualidade sob as quais a vida social está organizada. Para balizar a discussão em torno dessas experiências, acionei como aporte teórico alguns conceitos da Teoria Queer, vertente pós-estruturalista que questiona a essencialização dos sujeitos, as concepções de normatividade e o enrijecimento de experiências identitárias. Em seguida, busquei fazer uma interlocução com os debates sobre a atuação e campo teórico-metodológico da Terapia Ocupacional Social, refletindo sobre a dimensão prática e teórica das ações, visando o acesso à cidadania, sem perder de vista a urgência da compreensão dos fenômenos sociais, histórica e culturalmente. É preciso pensar nessas práticas sem perder de vista a posição de agente articulador dos sujeitos com a realidade social, a partir da mediação e ampliação de novas formas de fazer, da desnaturalização de vivências marginalizadas e, principalmente, da emancipação social, sempre articulando as dimensões macro com as micro, e o individual com o coletivo.
\end{abstract}

Palavras-chave: Heteronormatividade, Sexualidade, Gênero, Pós-Estruturalismo.

\section{Social Occupational Therapy, transgender and Queer Theory: (re)thinking normative conceptions based in gender and sexualities}

\begin{abstract}
This article seeks to discuss my trans experiences along with their developments arising from the normative conceptions of gender and sexuality in which social life is organized. To mark the discussion around these experiences, I used as theoretical goal some concepts of the Queer Theory such as the post-structuralism strand that questions the essentialism of subject, the normative conception and the stiffening of identity experiences. Furthermore, I sought an interlocution with the discussions on the occupational social therapy performance, analyzing the dimension of the practice and theory in actions aiming citizenship access, without losing sight of the urgent historical and cultural social phenomena understanding. It's necessary to think about these practices without losing sight of the coordinating agent position of the subject to the social reality, from the mediation and expansion of new ways of doing, the denaturalization of marginalized experiences and mainly of social emancipation, always articulating the macro dimensions with micro dimensions, and the individual with the collective.
\end{abstract}

Keywords: Heteronormativity, Sexuality, Gender, Post-Structuralism.

\footnotetext{
Autor para correspondência: Késia Maria Maximiano de Melo, Programa de Pós-graduação em Ciências Sociais, Universidade Estadual Paulista “Júlio de Mesquita Filho", Av. Hygino Muzzi Filho, 737, Mirante, CEP 17.525-000, Marília, SP, Brasil, e-mail: kesia_maximiano@yahoo.com.br

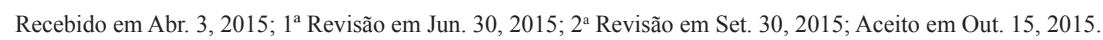




\section{Apresentação}

Este artigo é fruto de uma série de reflexóes que tenho desenvolvido a partir da pesquisa de campo etnográfico de minha dissertação de mestrado, intitulada Consciência, news e glamour: A internet como espaço alternativo de sociabilidade e articulaçáo política entre pessoas trans. Nessa pesquisa, procuro entender como a proliferação do acesso a internet tem interferido nas dimensóes políticas e subjetivas sobre as vivências trans, a partir desses espaços de interlocução virtual. Notadamente, as dinâmicas online entrecruzam-se com as vivências offline, e, portanto, o contato com o campo e com as informantes da pesquisa tem se dado nessas duas dimensóes. $\mathrm{O}$ contato não somente com as informantes, como também com a realidade social, histórica e cultural na qual elas estáo imersas, somado às minhas vivências como terapeuta ocupacional têm me proporcionado reflexôes sobre como as experiências de pessoas que desafiam a norma binária dos gêneros trazem para a cena e tensionam as nossas concepçôes sobre sociedade, vivência às margens, dinâmicas sociais e sobre a condução de nossas práticas profissionais na sua relação com o fazer humano, numa dimensão não somente prática como metodológica.

Desse modo, tomo como objetivo central nesse artigo, a análise das experiências trans baseada numa revisão bibliográfica da literatura já publicada sobre a temática, mais especificamente naquela que expressa as problemáticas decorrentes da privação do acesso a bens e serviços por parte dessa população, articulando-a com os pressupostos da Terapia Ocupacional Social.

Apresento ao longo do artigo, além da bibliografia já publicada, alguns relatos da minha pesquisa ainda em andamento, bem como algumas análises preliminares, numa tentativa de trazer essa reflexão para o campo da Terapia Ocupacional Social, entendendo inclusive a necessidade da compreensão de uma estrutura macro para o desenvolvimento de nossas práticas e para o nosso - necessário - posicionamento político. Para tal, venho me utilizando, metodologicamente, como baliza teórica e epistemológica de uma abordagem pós-estruturalista, mediada pelo debate sobre a não essencialização do sujeito, das identidades sociais e sobre a relação entre sexualidade e ordem social, da Teoria Queer. Essa teoria constrói seu pensamento a partir dos estudos culturais norte-americanos do final da década de 1980, como "[...] contraponto crítico aos estudos sociológicos sobre minorias sexuais è̀ política identitária dos movimentos sociais" (MISKOLCI, 2009, p. 150). O posicionamento crítico da Teoria Queer, seja em termos teóricos, seja em termos práticos, diz respeito às estratégias da disciplina para a normalização e estabilização das identidades sociais e das identidades de gênero. Esse posicionamento tem repercussão direta na crítica à heterossexualidade compulsória, à heteronormatividade, e busca pensar os mecanismos pelos quais esses elementos operam e ganham ressonância na vida cotidiana.

Os teóricos Queer retomam os estudos sobre sexualidade de Foucault (1988), entendendo-a como um dispositivo histórico do poder. A noção de dispositivo demarca uma conexão entre diversos elementos heterogêneos da vida social, como discursos, instituições, legislações, concepções, organizaçōes arquitetônicas, a filosofia, a ciência, moralidades e outros. A mediação de discursos sobre o sexo, articulados por esses elementos, toma como principal objetivo não a repressão, mas a regulamentação do sexo e, por consequência, de modos de vida. Parto dessa concepção teórica para refletir sobre as vivências de pessoas trans.

Ao longo dos últimos 20 anos, os estudos sobre pessoas trans ${ }^{1}$ vêm ganhando crescentes espaço e visibilidade no cenário acadêmico. Diversas são as áreas em que pesquisas têm sido desenvolvidas, sob a perspectiva da compreensão de como as vivências trans têm sido incorporadas pelos diversos sujeitos e pelo Estado, de como suas formas de ser e estar no mundo e de como essas vivências se desdobram nos múltiplos cenários da vida social.

Politicamente, especialmente no cenário brasileiro, os avanços no campo dos acessos ainda são muito restritos. A cidadania, como exercício e luta pela manutenção e ampliação dos direitos fundamentais para uma vida com dignidade ainda está longe de ser um bem democratizado, e se as políticas sociais são, em suma, o produto final entre os direitos sociais e a cidadania, quando pensadas a partir das necessidades das pessoas trans, ainda são bem escassas. O que Bento (2014) chama de "gambiarra de cidadania" ou "cidadania precária" é possível ser visualizado, por exemplo, na ausência de pessoas trans no mercado de trabalho formal, na ausência de políticas de saúde para além da prevenção de AIDS $^{3}$ e do processo de transgenitalização, ou no crescente número de assassinatos, principalmente de travestis.

Quando a Terapia Ocupacional Social se propóe a pensar as práticas cotidianas, a promoção de diversos espaços de acesso a bens e serviços e em como esses acessos podem promover construção e reconstrução de redes relacionais e de sociabilidade, tende a compreender a forma como essas vidas acontecem a partir de concepçóes normativas, o que acaba por desconsiderar a capacidade de agência dos 
sujeitos, bem como a possibilidade de que dentro dessas dinâmicas vividas à margem também existem centros, assim como nas vivências de centro existem margens.

Seguindo essa lógica, este artigo pretende, analiticamente, problematizar como, a partir das vivências trans, podemos pensar em formas de descentralizar as concepçôes normativas sobre os sujeitos e a vida cotidiana, para entáo favorecer, enquanto profissionais, os espaços de negociação do cenário social onde a vida desses sujeitos acontece. Para tal, discorro sobre as vivências trans que foram publicizadas por meio das pesquisas no campo das ciências humanas com maior intensidade nos últimos 20 anos para, a partir daí, pensar como a produção desse conhecimento abre um campo de diálogo entre eles e a Terapia Ocupacional Social.

\section{2 "Eu não sou homem, não}

\section{sou mulher, tenho direito de ser quem eu quiser!"': o que as vivências trans nos dizem sobre a vida cotidiana?}

A vida das pessoas trans vem mobilizando esforços de diversos pesquisadores no contexto acadêmico e fora dele. O campo de sociabilidade e as relaçóes políticas entre as pessoas trans foram estudadas em diversas etnografias, sob a perspectiva de compreender a experiência de ser ou tornar-se trans, o que possibilitou uma análise acerca de questôes que norteavam as práticas cotidianas delas, como as tecnologias e recursos utilizados para a realização das transformaçôes corporais (KULICK, 1998; VENCATO, 2002; BENEDETTI, 2005; BENTO, 2006; PELÚCIO, 2009); a manipulação das identidades sociais - partindo de uma nova geração de travestis (DUQUE, 2009); os conflitos identitários do movimento de travestis e transexuais no Brasil (CARVALHO, 2011); as possibilidades de acesso a equipamentos sociais e à rede de relaçóes (MONZELI, 2013). Além disso, estudos intensamente difundidos como os de Pelúcio (2009), Peres (2005) e Carrara e Vianna (2006) demonstram o constante processo de marginalizaçáo por parte de diversos setores sociais, tais como saúde, educação e segurança pública.

É preciso ressaltar que esses estudos não tiveram a pretensão de demonstrar que as pessoas compóem um grupo coeso e linear, com uma definição simplista, visto que defini-las enquanto grupo dentro de parâmetros rígidos engessaria essas experiências, ignorando seu caráter multifacetado e plural. Nessa direção, entendemos que as vivências trans são marcadas, sumariamente, pelo "embaralhamento dos gêneros” (PELÚCIO, 2009, p. 43).

Nos termos da Butler (2003), as pessoas trans imprimem em seu corpo a marca da subversão ao cruzar a fronteira dos gêneros e das sexualidades normativas. Normas e convençôes de gênero e sexualidade cunhadas pela matriz heterossexual acabam por alocá-las às marginalizaçôes que as segregam, visto que toda a esfera social está imbricada por uma série de fatores estabelecidos historicamente, determinando o que deve ou não ser aceito.

Os meninos afeminados, as jovens travestis, as gayrotas, as drag queens e as bichinhas assombram os códigos morais do presente. "Aterrorizam transeuntes que erguem o estandarte da família para justificar seu repúdio àquelas vidas indevidas" (PELÚCIO, 2011, p. 11). A vivência de homens trans também não tem sido diferente, embora marcada por questôes mais específicas, assim como a dos ditos gêneros não binários e das inúmeras outras formas de se construir e identificar.

Violência, "estupro corretivo", estigma, baixo acesso ao mercado de trabalho, políticas de saúde que não dão conta da complexidade de corpos que não correspondem ao que se espera moral e socialmente, uma mídia que propóe novas vivências de sexualidade e gênero timidamente mas que, ao mesmo tempo, as normatiza, criando novos roteiros de existência, a onda conservadora demonizando vivências náo pautadas na heterossexualidade e "cisgeneridade" $\mathrm{e}$ uma "autorizaçáo" social e moral para que não sejam tratados como sujeitos: essa tem sido a realidade e a luta cotidiana constante desses diversos sujeitos.

Atualmente, uma das principais pautas de discussão do Movimento Trans Brasileiro é o nome social. Algumas instituições garantem a modificação, em seus registro institucional, do nome segundo consta no registro civil para o nome social, a exemplo de algumas universidades públicas. No entanto, como discutido por Bento (2014), o nome social traz para análise dados que nos permitem pensar como as elites econômicas, políticas, raciais, de gênero e sexual se apropriam da estrutura do Estado para frear e impedir a ampliação e a garantia de direitos plenos às populaçóes que se encontram à margem. Em outras palavras, em lugares específicos, pessoas trans tem o "direito" de ser reconhecidas mediante a sua identidade de gênero tal qual se identifica, no entanto, nos demais espaços, continuam sendo chamados/as pelo nome do registro, o que impede o reconhecimento desses sujeitos como "pessoas de direito". Segundo a vivência de algumas mulheres 
$\operatorname{trans}^{6}$ que conseguiram juridicamente realizar a alteração do nome no registro civil, quando o Estado reconhece o nome de pessoas trans como aquele que se coaduna com a sua identidade pessoal e social, a vivência social no campo dos acessos e do direito tem se mostrado menos violada.

Se o nome é o bilhete de entrada em qualquer espaço que se queira acessar, e se essa questão nos parece simples, a vivência de pessoas trans no que tange a essa problemática tem sido não somente desgastante mas precarizada. Nessa direção, ainda de acordo com Bento (2014), há uma dupla negação: a da condição humana e de cidadão/cidadã de sujeitos que carregam no corpo determinadas marcas.

Essa dupla negação está historicamente assentada nos corpos das mulheres, dos/as negros/as, das lésbicas, dos gays e das pessoas trans (travestis, transexuais e transgêneros). Para adentrar a categoria de humano e de cidadão/cidadá, cada um desses corpos teve que se construir como "corpo político". No entanto, o reconhecimento político, econômico e social foi (e continua sendo) lento e descontínuo (BENTO, 2014, p. 167).

Em se tratando de espaços de sociabilidade, o estigma e o preconceito têm marcado essas vivências. Diversas etnografias realizadas entre os anos de 1993 e 2012 demonstram que a "pista" tem sido um dos principais espaços em que as mulheres trans e, mais especificamente, as travestis experimentam uma sociabilidade, constroem vínculos relacionais e desenvolvem um senso de pertencimento (SILVA, 1993; KULICK, 1998; BENEDETTI, 2005; PELÚCIO, 2009; DUQUE, 2009). Mais recentemente, ainda dentro do movimento trans brasileiro, um debate tem sido levantado ${ }^{8}$ : as mulheres trans têm conseguido acessar outros espaços no mercado de trabalho, além da prostituição, no entanto, o número ainda é bem reduzido, e esses espaços têm sido, predominantemente, caracterizados por atividades em que não há necessidade da exposição corporal, tais como atividades em agências de telemarketing. A inserção em espaços em que a corporalidade é invisibilizada tornam clara a dinâmica sustentada pela lógica de que a subversáo a partir de um corpo que borra a fronteira entre os gêneros relega espaços numa equação quase que precisa, e moralmente muito pouco questionada.

Anteriormente ao mercado de trabalho, a escola tem sido mencionada em diversas pesquisas como lugar de opressão no que diz respeito às vivências de pessoas trans. Silva (2008) discute que se, a partir de uma concepção mais generalizada, a escola é o local da inclusão, e da passível convivência das diferenças, bem como do acesso democrático ao conhecimento, para as pessoas trans, a escola é um local que marca uma vivência de intenso sofrimento, reforço de estigmas, de violência e ataque cotidiano à sua autoestima, abortando diversas possibilidades de conquistas materiais e sociais futuras. Destaco aqui uma das problemáticas mais discutidas nas investigaçôes sobre essas experiências: o uso do banheiro. Se o espaço da sala de aula parece hostil para quem faz uso de adereços tidos como inapropriados para o seu gênero, o uso do banheiro simbolicamente se transforma numa vivência marcada por proibiçôes, possibilidades de violência (física e psicológica) e denominaçóes que não se encaixam nas autoidentidades.

A porta (do banheiro) com um símbolo masculino ou feminino funciona como um filtro que, além de separar os elementos, acaba identificando e expondo uma diferença (MONZELI, 2013, p. 63).

Embora atualmente, especialmente através das plataformas de sociabilidade virtual, seja possível ter contato com relatos de vivências de travestis, mulheres trans e homens trans que têm acessado espaços como a universidade, tornando-se alunos do ensino superior, essa vivência ainda não é predominante, mas está evidentemente ligada a algumas transformaçóes sociais decorrentes das políticas de acesso ao ensino superior dos últimos anos de gestão do Estado brasileiro. No entanto, neste artigo, não tenho a pretensão de centralizar meus esforços em tais questóes, reconhecendo que para isso é necessário um amplo debate.

No cenário da manutenção do binômio segurança-violência, quando pensado a partir de uma perspectiva trans, essa relação ganha um contorno mais visível. De acordo com Jesus (2012), a América Latina é a região do globo onde mais se matam travestis e transexuais. Segundo a pesquisadora e ativista trans, a gravidade dos dados coletados no Brasil entre 2008 e 2011 acentua-se quando se compara esse número de assassinatos transfóbicos com o de outros países com nível semelhante de liberdade de imprensa e de mobilização social, fatores que aumentam a probabilidade de divulgação de crimes de ódio.

\section{3 “Dá o nome, Mona!":} pensando as contribuições da Terapia Ocupacional nessas
vivências

Se ao desestabilizar as concepções binárias entre os gêneros, as pessoas trans vêm sendo, historicamente, relegadas a espaços marginais e deslegitimadas enquanto 
sujeitos, o acesso a determinadas possibilidades tecnológicas associada a transformaçóes sociais e políticas tende a modificar a forma com que elas experienciam os sentidos atribuídos à viver na fronteira entre os gêneros e buscam alternativas de enfrentamento em relaçáo aos mecanismos que mantêm a delimitação de espaços, dinâmicas e direitos, bem como a privaçáo da cidadania.

Nessa direção, pensar na Terapia Ocupacional como uma profissão que, de acordo com Barros (2004), tem a cidadania como eixo de seu escopo e que encontra em seu campo de atuaçáo um olhar especificamente voltado para os sujeitos, o fazer humano e as significações e ressignificações desse fazer no cotidiano significa pensar como compreender essas vivências exige uma construçáo, desconstrução e reconstrução constante sobre como os processos normativos incidem nas formas de viver e, mais do que isso, como esses processos ganham ressonância nos espaços a serem acessados, nas vidas a serem construídas e na autorização que o Estado e a sociedade como um todo ganham para desligitimar sujeitos e delimitar em quais margens eles irão transitar.

Atualmente, a Terapia Ocupacional Social vem sendo amplamente debatida no sentido de pensar suas bases tanto no aspecto teórico-metodológico quanto no que diz respeito às práticas. De acordo com Barros (2004), ela pode contribuir no que diz respeito a equacionar questóes que se impóem pelas desigualdades, contradiçóes sociais e confrontos culturais. No entanto, enfatiza o risco de se oferecer uma leitura psicologizante para fatos históricos e para as contradiçôes da dinâmica social. Para tal, de acordo com a autora, deve-se pensar o

[...] processo de conhecimento plural, e na criaçáo de espaços para um diálogo entre o que é local e o que o transcende - mas náo o elimina (BARROS, 2004, p. 95).

Nesse sentido, estando os sujeitos inseridos em um contexto político, social e econômico mas não necessariamente dotado de homogeneidade, pensar nessas vivências à margem e nas nossas possibilidades de intervençáo requer, primeiramente, que questionemos quais as dinâmicas que essas vivências assumem e o que, socialmente, as autoriza e legitima, para que então possamos nos posicionar enquanto agentes políticos.

$\mathrm{Na}$ vivência de pessoas trans, o que temos encontrado em comum é a subversão das normas que regulamentam os gêneros (BUTLER, 2003). Se pensarmos essa subversão a partir de uma perspectiva Queer, podemos observar que o principal fundamento que autoriza a não legitimidade das experiências trans é a heteronormatividade. Essa advém de uma heterossexualidade compulsória (BUTLER, 2003), e, partindo da reflexão de Sedgwick (2007), a ordem social contemporânea não difere de uma ordem social, o dualismo hetero/homo se estrutura de forma a "[...] priorizar a heterossexualidade por meio de um dispositivo que a naturaliza e, ao mesmo tempo, a torna compulsória" (MISKOLCI, 2009, p.156). Assim, a heteronormatividade sustenta-se no argumento da heterossexualidade como natural e organiza a vida dos sujeitos a partir de uma série de prescriçóes baseadas nesse pressuposto.

A heteronormatividade marca até mesmo aqueles que não se relacionam com pessoas do sexo oposto. As formas de definir a si mesmo de várias culturas sexuais não hegemônicas seguem a heteronormatividade, o que é patente na díade ativo/passivo dos gays, a qual toma como referência a visão hegemônica sobre uma relação sexual reprodutiva para definir papéis/posiçóes sexuais. Assim, a heteronormatividade não se refere apenas aos sujeitos legítimos e normalizados, mas é uma denominação contemporânea para o dispositivo histórico da sexualidade que evidencia seu objetivo: formar a todos para serem heterossexuais ou organizarem sua vida a partir do modelo supostamente coerente, superior e "natural" da heterossexualidade (MISKOLCI, 2009, p. 5).

Se pensarmos a heretonormatividade sem restringi-la a uma concepção de heterossexualidade, perceberemos que ela está completamente ligada a formas de organização da vida social, modelos, papéis e práticas, e se a Terapia Ocupacional se propõe a lidar com o fazer humano dentro da sua complexidade, é preciso considerar que ela está diretamente relacionada com a forma como se constituem as práticas cotidianas, as dimensôes espaciais e relacionais dos acessos e das sociabilidades, com configuração das políticas sociais, entre outras.

Tomando essas concepçóes como base de uma problemática, podemos questionar: Quantas travestis, em nossas vivências práticas, temos visto assumindo a chefia de uma grande empresa? Quantas transexuais médicas temos encontrado? Quantas drag queens juízas têm sido vistas nos tribunais? A heteronormatividade precisa ser questionada para que se abra a possibilidade de que outras vivências sejam não somente visíveis como possíveis.

Além disso, direitos básicos como maternidade e paternidade têm sido privados de pessoas que não encontram linearidade na tríade sexo-gênero-desejo. 
A intensa discussão sobre a adoção de crianças por casais homossexuais tem sido pauta nos diversos espaços de construção de políticas e leis, e o registro dessas vivências por pessoas trans tem sido tão pouco visível quanto realizável.

As concepçóes de maternidade, por exemplo, são ligadas à feminilidade e, logo, a um corpo com vagina, mostrando como a heteronormatividade é não somente naturalizada como mantida. O gênero é compreendido para além da mera representação de papéis a serem desempenhados por corpos de homens e mulheres sob a hegemonia da heteronormatividade, essa é, primeiramente, uma complexidade permanentemente aberta. Assim,

[...] gênero é uma representação que é vivenciada pelas performances dos sujeitos sociais que a experienciam através da vivência espacial cotidiana e concreta (SILVA, 2008, p. 91).

De acordo com Butler (2003), a construção de gênero é marcada também pela noçáo de performatividade. Esse conceito determina que o gênero tem a ver com a reiteração de normas que são anteriores ao agente e que são permanentemente reiteradas, materializando aquilo que nomeiam. Assim,

[...] as normas reguladoras do sexo são performativas no sentido de reiterarem práticas já reguladas, materializando-se nos corpos, marcando o sexo, exigindo práticas mediante as quais se produz uma "generificaçáo". Não se trata, portanto, de uma escolha, mas de uma coibição, ainda que essa não se faça sentir como tal. Daí seu efeito a histórico, que faz desse conjunto de imposiçóes algo aparentemente "natural" (MISKOLCI; PELÚCIO, 2007, p. 260).

Os gestos, os signos, os códigos e as práticas expressas e impressas no corpo produzem identidades, instituindo configuraçôes delimitadas que não necessariamente encontrarão coerência entre os elementos - sexo-gênero-desejo -, que estão em permanente transformaçáo e sempre abertos ao novo. Não encontrar coerência nessa tríade torna claro o fato de que a prescrição de normas em nada garante que esses corpos a vivam, já que "os corpos escapam" (BUTLER, 2002, p. 42). E aos corpos que escapam, o lugar que lhes é relegado é o da abjeção.

Retomando discussão proposta por Julia Kristeva ${ }^{9}$, Butler (2003) define a abjeçáo do corpo como aquele que

foi expelido, descartado, tornado literalmente como o "Outro". E, embora, segundo a autora isso pareça uma expulsão de elementos estranhos: "é precisamente através dessa expulsão que o estranho se estabelece". A construção do "não eu" como abjeto estabelece as fronteiras do corpo, que são também os primeiros contornos do sujeito (BUTLER, 2003, p. 190-191).

Embora opere na direção do que entendemos por exclusão ou pela ausência de direitos, a abjeção, anterior a isso, engendra seus mecanismos por meio da ausência de reconhecimento e legitimidade diante da vida social, baseando-se na diferença, assim como vivem as pessoas trans ao borrarem a fronteira entre gêneros, ou os segmentos que subvertem a ordem compulsória que relaciona um sexo a um gênero, a um desejo heterossexual e a uma série de práticas baseadas em concepçôes heteronormativas. A abjeção, então,

[...] opera como lugar da não aceitação do que é considerado monstruoso, odiado, vomitável, infame e anormal ao ameaçar os padróes controláveis e previsíveis (SILVA; SILVA, 2013, p. 63).

É relevante considerar, além do gênero e da sexualidade como marcadores sociais da diferença, a interseccionalidade que reforça as dinâmicas de marginalização desses sujeitos, tais como raça, geração, etnia, religião, classe social, entre outros.

Assim, se problematizarmos de que modo essas concepçôes de naturalização e de desnaturalização encontram ressonância na vida social, chegaremos a uma série de negociaçôes cotidianas, mas principalmente ao náo reconhecimento social e, consequentemente, à não garantia de certos direitos e, principalmente, da cidadania.

No feixe que as açóes da Terapia Ocupacional Social adotam como eixo central, a elaboração de estratégias para a criação e/ou fortalecimento das redes sociais de suporte a sujeitos em contextos de vulnerabilidade, norteadas pelo direito a cidadania (LOPES et al., 2010, p. 146), a realidade social, cultural e política das pessoas trans deve ser pensada a partir, principalmente, das políticas públicas e da desnaturalização da norma enquanto roteiro de vida que dita quem se é e "como se deve ser".

A restrição tem repercussão direta na forma como essas vidas serão vividas, no reforço aos estigmas e na própria dimensão subjetiva sobre si. Conforme Monzeli (2013), articulando os níveis macrossocias e micropessoais e discutindo a disponibilização de serviços mais inclusivos e a conscientização/participação da comunidade e desses sujeitos no processo de resolução de problemas, a Terapia Ocupacional 
pode contribuir com a ressignificaçáo dos espaços públicos e institucionais, promovendo experiências de acesso e de novos modos de fazer.

Se as experiências trans têm sido balizadas pela invisibilidade de uma possibilidade de viver com dignidade e se as formas de subjetivação, práticas e modelos de vida que lhe são impostos adotam como base os discursos hegemônicos heteronormativos, a Terapia Ocupacional deve amparar-se não somente nessas experiências para pensar estratégias de inclusão como também nos mecanismos que os reforçam, buscando a dimensão de uma prática que extrapole os limites do sujeito individue al que dimensione a urgência de intervençóes pautadas no coletivo, na estrutura e no trânsito social.

"Não há como desprender-se do debate de que as experiências constroem os sujeitos" (SCOTT, 1998, p. 299) mas os sujeitos também constroem a experiência, e que há uma dimensão subjetiva dessas vivências que são permeadas por intensas negociações diárias por meio das quais os sujeitos são significados. Compreender essas negociaçóes e esses significados exige o reconhecimento de diferentes concepçóes sobre os espaços e sobre o fazer cotidianos.

Nessa dimensão, no campo social, o profissional é convidado para além do desenvolvimento do trabalho, numa perspectiva individual e institucional, devendo assumir também um papel de articulador social, sendo suas demandas a reflexão e produção de intervençóes que estejam relacionadas ao domínio "[...] macroestrutural e conceitual, o político-operacional e o da atenção pessoal e coletiva" (GALHEIGO, 1999, p. 24).

De acordo com Malfitano (2005), a Terapia Ocupacional no campo social prevê uma intervenção calcada nos conceitos de autonomia, cidadania e direito, direcionadas a possibilitar o alcance dos desejos e necessidades do sujeito, bem como a ampliação de vivências e repertórios socioculturais para sua vida. Assim, nesse contexto, mais do que intervir no sentido de pensar a ampliação de vivências nos múltiplos espaços sociais, é preciso considerar a necessidade de se pensar na criação de possibilidades, sem criar novos roteiros normativos, e prescriçóes sobre como ser uma pessoa trans "que se pode adequar". Ampliar o repertório, nesse contexto, tem a ver com considerar possibilidades de escolha e pensar em estratégias de como elas podem ser acessadas, seja no que diz respeito à escola, ao trabalho, aos múltiplos espaços de circulação ou a relaçóes sociais-afetivas.

O investimento nas possibilidades de criação e apoio de diferentes formas de resistência individual e coletiva à desumanização mostra-se essencial nesse contexto, colaborando e incentivando em conjunto formas de experimentação, aprendizagem, ensino e criação que combatam as desigualdades e contribuam para a construção de pontes de acesso a direitos, para a elaboração e mobilização de processos orientados para a emancipação pessoal (ALMEIDA et al., 2011, p. 353).

De forma desafiadora, a atuação no campo social exige do terapeuta ocupacional um desconstruir e reconstruir constantes. A possibilidade do conflito entre as nossas concepções pessoais de vida e a realidade sobre a qual podemos nos debruçar é latente. $\mathrm{O}$ que se entende a partir de uma vivência pessoal como uma experiência positiva pode imobilizar completamente a capacidade de agência do outro e, nesse sentido, não há como desprender-se do contexto histórico e cultural de um determinado segmento ao se pensar as nuances de uma abordagem com e para ele. Assim, as proposiçóes partem de um posicionamento epistemológico e se desdobram em um posicionamento que, acima de tudo, é político.

No caso das pessoas trans não seria atípico (o que não implica dizer que seria uma regra) deparar-se com uma travesti que se prostitui e que náo tem pretensão de parar de se prostituir. E, ainda: que goste dessa vivência e a signifique de forma positiva, prática e subjetivamente. Compreender a dimensão simbólica e prática dessa vivência é uma das bases norteadoras da atenção e, nessa direção, a proposição de alternativas em que ela possa manter-se na prostituiçáo de forma digna deve ser pensada como uma das possibilidades e, mais do que isso, é importante que possamos pensar que se prostituir, nesse cenário, tem que ser uma das opções e não a única.

\section{Considerações finais}

O que busquei propor por meio das reflexôes suscitadas neste artigo não tem nada de conclusivo. Enrijecer as possibilidades de debate, ao se falar de uma perspectiva Queer é demasiado contraditório e, portanto, problemático. Debrucei-me sobre essas proposiçóes numa tentativa de incitar um debate sobre (outras) formas de ser e existir no mundo e, principalmente, sobre como, politicamente, em muitas medidas, nem mesmo a gramática social tem dado conta de incorporar as vivências trans no repertório das possibilidades de acesso a bens e serviços e, consequentemente, de uma vida com dignidade. 
Se formas de subjetivação, práticas e modelos de vida são impostos a partir de discursos hegemônicos heteronormativos, e se esse reforça cotidianamente que o espaço a ser ocupado pelas pessoas trans é o das margens, tomando como justificativa a "incoerência entre gênero, sexo e desejo" (BUTLER, 2003, p. 30), a realidade atual nos diz que há possibilidades de intervenção no sentido de pensar os mecanismos que limitam esses sujeitos às margens.

É inegável que atualmente o debate tem avançado e ganhado contornos em diversos espaços, tais como os movimentos sociais, as mídias digitais, a mídia televisionada, a academia, a câmara de direitos humanos, entre outros, mas ainda existe muito a ser construído e mais ainda a ser desconstruído. É nesse cenário que penso que a Terapia Ocupacional tem muito a contribuir.

Os lugares de enunciação, a crítica política e o empoderamento exigem um descentramento sobre as concepçóes naturalizadas de sujeito e, consequentemente, das práticas cotidianas. A cidadania há muito vem sendo heterossexual, branca, cristã e ocidental, mantendo-se num lugar bem distante da neutralidade. Ela tem relação direta com a forma como os corpos são dispostos socialmente e com o modo como eles são alocados baseados na mensuração do quanto se está dentro de parâmetros que legitimam quem é ou não sujeito de direito.

Nesse sentido, as práticas cotidianas enquanto lugar de ação do terapeuta ocupacional devem ser pensadas sem perder de vista esses sujeitos, e principalmente, o contexto histórico, cultural e social no qual eles estão imersos.

\section{Referências}

ALMEIDA, M. C. et al. Terapia ocupacional e pessoas em situação de rua: criando oportunidades e tensionando fronteiras. Cadernos de Terapia Ocupacional da UFSCar, São Carlos, v. 19, n. 3, p. 351-360, 2011.

BARROS, D. D. Terapia ocupacional social: o caminho se faz ao caminhar. Revista de Terapia Ocupacional da Universidade de São Paulo, São Paulo, v. 15, n. 3, p. 90-97, 2004.

BENEDETTI, M. Toda feita: o corpo e o gênero das travestis. Rio de Janeiro: Garamond, 2005.

BENTO, B. A reinvenção do corpo: sexualidade e gênero na experiência transexual. Rio de Janeiro: Garamond, 2006.

BENTO, B. Nome social para pessoas trans: cidadania precária e gambiarra legal. Contemporânea, São Carlos, v. 4, n. 1, p. 165-182, 2014.

BUTLER, J. Cuerpos que importan. Barcelona: Paidós, 2002.
BUTLER, J. Problemas de Gênero: feminismo e subversão da identidade. Rio de Janeiro: Civilização Brasileira, 2003.

CARRARA, S.; VIANNA, A. "Tá lá o corpo estendido no chão...”: a violência letal contra travestis no município do Rio de Janeiro. Physis, Rio de Janeiro, v. 16, n. 1, p. 233-249, 2006.

CARVALHO, M. Que mulher é essa? Identidade, política e saúde no movimento de travestis e transexuais. 2011. 208 f. Dissertação (Mestrado em Saúde Coletiva) - Universidade Federal do Rio de Janeiro, Rio de Janeiro, 2011.

DUQUE, T. Montagens e desmontagens: vergonha, estigma e desejo na construção das travestilidades na adolescência. 2009. 194 f. Dissertação (Mestrado em Sociologia) - Universidade Federal de São Carlos, São Carlos, 2009.

FOUCAULT, M. História da Sexualidade I: a vontade de saber. Rio de Janeiro: Ediçóes Graal, 1988.

GALHEIGO, S. M. Repensando o lugar do social: a constituição de um campo de conhecimento em terapia ocupacional. In: CONGRESSO BRASILEIRO DE TERAPIA OCUPACIONAL, 6., 1999, Águas de Lindóia. Anais... Águas de Lindoia, 1999.

JESUS, J. G. Identidade de gênero e políticas de afirmação identitária. In: CONGRESSO DA ABEH, 6., 2012, Salvador. Anais... Salvador: Associação Brasileira de Estudos da Homocultura, 2012.

KULICK, D. Travesti: sex, gender and culture among Brazilian Transgendered Prostitutes. Chicago: University of Chicago Press, 1998.

LOPES, R. E. et al. Educação profissional, pesquisa e aprendizagem no território: notas sobre a experiência de formação de terapeutas ocupacionais. O Mundo da Saúde, São Paulo, v. 34, n. 2, p. 140-147, 2010.

MALFITANO, A. P. S. Campos e núcleos de intervenção. Revista de Terapia Ocupacional da Universidade de São Paulo, São Paulo, v. 16, n. 1, p. 1-8, 2005.

MISKOLCI, R.; PELÚCIO, L. Fora do sujeito e fora do lugar: reflexóes sobre performatividade a partir de uma etnografia entre travestis. Gênero, Niterói, v. 7, n. 2, p. 257-269, 2007. Disponível em: <http://www. revistagenero.uff.br/index.php/revistagenero/article/ view/155/98>. Acesso em: 3 abr. 2015.

MISKOLCI, R. A Teoria Queer e a sociologia: o desafio de uma analítica da normalização. Sociologias, Porto Alegre, v. 11, n. 21, p. 150-182, 2009. Disponível em: <http://www.scielo.br/pdf/soc/n21/08.pdf>. Acesso em: 3 abr. 2015.

MONZELI, G. Em casa, na pista ou na escola é tanto babado: espaços de sociabilidade de jovens travestis. 2013. 151 f. Dissertação (Mestrado em Terapia Ocupacional) - Universidade Federal de São Carlos, São Carlos, 2013. 
PELÚCIO, L. Abjeção e desejo: uma etnografia travesti sobre o modelo preventivo de aids. São Paulo: Annablume, 2009.

\section{PELÚCIO, P. Apresentação. In: DUQUE, T. Montagens} e desmontagens: desejo, estigma e vergonha entre travestis adolescentes. São Paulo: Annablume, 2011. p. 19-24.

PERES, W. Subjetividade das travestis brasileiras: da vulnerabilidade da estigmatização à construção da cidadania. 2005. 201 f. Tese (Doutorado em Saúde Coletiva) - Universidade Estadual do Rio de Janeiro, Rio de Janeiro, 2005.

SCOTT, J. W. A Invisibilidade da experiência. Projeto História, São Paulo, n. 16, p. 303-304, 1998.

SEDGWICK, E. K. A epistemologia do armário. Cadernos Pagu, Campinas, n. 28, p. 19-54, 2007.
SILVA, H. Travesti: a invenção do feminino. Rio de Janeiro: Relume-Duramá, 1993.

SILVA, J. M. A cidade dos corpos transgressores da heteronormatividade. Geo UERJ, Rio de Janeiro, v. 1, n. 18 , p. $1-17,2008$. Disponível em: <http:/www.e-publicacoes.uerj.br/ojs/index.php/geouerj/article/ view/1343/1132>. Acesso em: 03 abr. 2015.

SILVA, G. C.; SILVA, J. M. M. O ensino superior como lugar não homologado da abjeção e da diferença: sobre o devir homoerotismo. Revista do Difere, Belém, v. 3, n. 6, p. 1-14, 2013. Disponível em: <http://www.artificios.ufpa.br/Artigos/Revista6/Dossie\%20gerlandia\%20 e\%20jose.pdf>. Acesso em: 03 abr. 2015.

VENCATO, A. P. Fervendo com as drags: corporalidades e performances de drag queens em territórios gays da Ilha de Santa Catarina. 2002. 124 f. Dissertaçáo (Mestrado em Antropologia Social) - Universidade Federal de Santa Catarina, Florianópolis, 2002.

\section{Fonte de Financiamento}

Coordenação de Aperfeiçoamento Pessoal de Nível Superior - Bolsa CAPES.

\section{Notas}

${ }^{1}$ Entendo pessoas trans, neste artigo, a partir do que a filósofa norte-americana Judith Butler (2003) propốe enquanto corpo abjeto. Esses sujeitos não obedecem ao que se espera na construçáo de sua vivência em torno do gênero. De acordo com a autora, há uma ordem compulsória no sistema sexo/gênero/desejo em que o que se espera de uma pessoa com uma genitália feminina é que ela seja mulher, se relacione com homens e desenvolva práticas baseadas naquilo que se entende como práticas "femininas". Quando algum corpo escapa a essa lógica, é tido como um corpo abjeto. Entendo neste artigo que as vivências trans são vivências abjetas.

${ }^{2}$ A socióloga brasileira propóe tal conceito para demonstrar como, no campo dos acessos, as pessoas trans estão relegadas ao alcance de direitos de forma precária, ou seja, historicamente, os grupos tidos como "minorias" somente alcançaram direitos básicos e fundamentais após o avanço dos mesmos direitos para a sociedade normativa, e após anos de lutas. A autora ainda ilustra o conceito a partir da problematização do direito ao voto das mulheres, ou da abolição da escravatura.

${ }^{3}$ Vale ressaltar que, segundo a pesquisa de doutorado da antropóloga Larissa Pelúcio (2009), o modelo preventivo de AIDS brasileiro coloca travestis e pessoas trans em geral como pertencentes a grupos de risco, o que não é epidemiologicamente correto nem socialmente eficaz, estigmatizando esses sujeitos.

${ }^{4}$ Palavras de ordem da Marcha da Cidadania T, organizada pelo Movimento Trans Brasileiro, durante o IX Encontro Nacional de Travestis e Transexuais, ocorrida em 14 de dezembro de 2014, na cidade de Sáo Paulo.

${ }^{5} \mathrm{O}$ termo é atualmente utilizado para determinar pessoas que não desafiam as normas de gênero, uma vez que vivem a "coerência" sobre o que se espera da linearidade sexo/gênero. Embora o termo fixe uma identidade, o que epistemologicamente náo favorece o debate, tem sido usado como uma estratégia de pessoas trans no sentido de demonstrar o incomodo de serem nomeados por pessoas que não tem as mesmas vivências que as suas.

${ }^{6}$ Tive acesso a alguns relatos dessa natureza durante a minha pesquisa de mestrado, ainda em andamento.

${ }^{7} \mathrm{O}$ termo pista é comumente utilizado para referir-se a locais públicos de prostituição, tais como praças, esquinas, entre outros.

${ }^{8}$ Também tive acesso a esses dados durante a minha pesquisa de mestrado.

${ }^{9}$ A autora, em forte diálogo com a psicanálise freudiana, lacaniana e winnicottiana, aproxima a abjeção de uma existência primitiva do capital psíquico, uma espécie de negação do eu em constituição deste. Um lugar de fronteira, de negação e produção, ao projetar um corpo desprovido de alma cuja principal manifestação correlata é a do cadáver. Embora atue como produção, a abjeção se manifesta como ausência, negação, um não limite, um vácuo que abre espaço para a desestruturação de regras e princípios morais, éticos, políticos e religiosos que escapam ao controle e ao governo e embaraça as identidades (SILVA; SILVA, 2013). 